\title{
Understanding the Ties that Bind and the Possibilities for Change
}

\section{By: David J. Teachout}

Teachout, D. J. (2007). Understanding the ties that bind and the possibilities for change. Arts Education Policy Review 108(6), 19-32. Reprint of invited chapter in R. R. Rideout (Ed.) Policies and practices: Rethinking music teacher preparation in the 21st century (pp.81-89). Amherst, MA: University of Massachusetts Department of Music and Dance.

This is an Accepted Manuscript of an article published by Taylor \& Francis in Arts Education Policy Review on July 2007, available online: http://www.tandfonline.com/10.3200/AEPR.108.6.19-32.

\begin{abstract}
:
The author describes how contemporary music education at the secondary level has fallen short of Dr. Charles Leonhard's vision for developing musical understanding and musical responsiveness in all students and cites several historical events as pivotal in promoting the profession's current path. The author then challenges this generalization by describing the professional practices of a forward-thinking high school band director who epitomizes Leonhard's ideal of a music teacher and serves as a model for professional dispositions. The author also offers social interaction theory as a promising foundation on which to assemble a music teacher education program capable of producing teachers with dispositions that serve the highest goals of the music education profession.
\end{abstract}

Keywords: music education | music teacher education | professional dispositions | secondary level | social interaction theory

\section{Article:}

I preface this article with two considerations: (a) before rethinking music teacher education for the twenty-first century, we need to consider what music education in the twenty-first century could and should be and (b) my ideas are directed toward music education at the secondary level and toward preparing undergraduates to teach at that level.

In November 2005, a convocation titled A Weekend of Remembrance, Celebration, and Dedication was held at the University of Illinois to honor the life and career of Dr. Charles Leonhard. Although I did not have the privilege of knowing Dr. Leonhard, I can imagine he would have been heartened to know we are moving beyond paying homage to him and going forward with ideas and research to further our understanding of preparing music teachers for the challenges of the twenty-first century.

In the effort to get to know Dr. Leonhard, I read and reread many of his writings and the writings about him by colleagues and former students. Along with stories of his bold mannerisms, classroom demeanor, rye sense of humor, and quick wit, I learned what he believed to be important about music education-that its purpose was to "develop the aesthetic potential, 
possessed by every human being, to its highest level" (Leonard and House 1972, 3). He believed "participation in the music program [provides] students a creative mode [through] which they can enrich their lives through self-expression and response to the expression of others" (Leonhard 1985, 11). A principle often touted among contemporary leadership circles is "begin with the end in mind" (Covey 1989, 97). It is simplistic and yet, when followed, provides a wonderfully effective strategy for prioritizing one's attention appropriately. In the case of music education, Charles Leonhard was very clear about the goal. The role of music instruction in education is to provide a richer life (Leonhard 1964).

\section{Contemporary Music Education Is Not Hitting Its Mark}

Richer living is reflective of aesthetic responses to musical experiences and the quality of such responses is dependent on the degree to which one is able to engage musical experiences with knowledge, skills, and dispositions. Music education should be about developing such musical knowledge, skills, and dispositions to demystify music and afford all students opportunities for higher levels of independent engagement with music. I am afraid that contemporary music instruction in the schools is not achieving this goal.

A close friend and colleague related a story to me recently about his thirteen-year-old daughter, Olivia. Olivia has been a member of her school band program for three years and has taken piano lessons for four. A year ago, she was recruited to join a community league soccer team. Prior to joining the team, she had no experience with the sport. On joining, she received a uniform and began to attend regularly scheduled practices in which she learned the rules of the sport, various playing positions, and some basic strategies for success. After a short induction period, Olivia was coming up with inventive plays, ways to make the team more successful, and found herself being valued by her friends and coaches for her ideas and contributions. There were powerful sociological principles at work here, but more on that later. Olivia was thoroughly invested in being a soccer player. When noticing this strong effect, her dad decided to conduct an informal bit of action research. He asked her, "Olivia, are you a soccer player?" to which she enthusiastically replied "You betcha!" Then he asked, "Olivia, are you a musician?" Her response was, "No. Not yet, but I am trying."

One could make the argument that being a musician is far more complex than being a soccer player and Olivia is simply displaying a healthy respect for the discipline of music. Perhaps the difference does not lie so much in the complexity of the two types of activities, but in how these activities are experienced. Marzano et al. (1988) present twenty-one "core thinking skills" as a foundation for the development of critical thinking (68). Apfelstadt (1989) elaborated on this material by hierarchically categorizing core thinking skills into low (focusing, information, remembering), middle (gathering, organizing, integrating), and upper (analyzing, generating, and evaluating) levels of thinking, similar to Bloom's taxonomy (1956). When Olivia is engaged in a soccer match she is challenged at all levels of thinking simultaneously. She must know and remember the rules of the game and strategies she learned in practice. Furthermore, she must observe carefully movements of the opposing team in the effort to gather, organize, and integrate new information. Then she must analyze information, generate new strategies, and evaluate whether the new strategies were successful. The most notable characteristic of Olivia's engagement with soccer is that her experience of success is immediate and personal. Whether 
she is attempting to direct the ball to one of her teammates, kick it down the field, or score a goal, she does not need to rely on the coach or any other outside figure to know when she has been successful. Olivia is completely in charge of her domain as a soccer player.

Contrast Olivia's soccer experience with that typically found in the most common public school music offering at the secondary level-the large ensemble rehearsal. In the rehearsal setting, the teacher performs nearly all decision-making actions. "Trumpets, that's a B-flat not a B-natural." "Sopranos, sing that top pitch softer." "No, violins-you are rushing the tempo; let's try it again, and hold back this time." Meanwhile, students obediently follow the teacher's instructions, hoping to eventually receive some indication they have achieved the goal. Any degree of gathering, organizing, and integrating information for the purpose of analyzing and evaluating the situation is usually directed toward the goal of pleasing the teacher and avoiding a reprimand rather than toward the business of developing one's artistic expertise. Although this depiction is somewhat harsh and at the extreme end of the spectrum, my experience tells me the profession is not characterized by a normal curve, but rather is skewed toward this extreme. Olivia's tentative response when being asked whether she considered herself a musician is indicative of the infrequent opportunities she has been provided to individually claim that role. Olivia's engagement with music is not immediate and personal. She is not in charge of her domain as a musician and she knows it.

From an outsider's perspective, music education in the schools could easily be considered a genuine success. Music has been included in the public school curriculum since 1838 and is characterized officially by a nationally recognized set of content standards. Music is a visible and expected component of such hallmarks of public school life as Friday night football games, school PTA meetings, and seasonal and holiday concerts. Furthermore, school music programs in other countries rarely top the performance quality of large ensembles in United States. Yet, Olivia's story is emblematic of the very real way in which the profession has fallen short. Few students graduate from their public school music programs with an empowered sense of independent musicianship and with, as Leonhard states, "the ability to enrich their lives through self expression" $(1985,11)$.

I am reminded of a professional meeting that I attended several years ago with music education faculty from a number of large research universities. Several individuals from disciplines outside of music spoke over the course of the weekend. The meeting assembled experts from the fields of anthropology, sociology, and psychology to provide us with a thought-provoking backdrop against which to view our discipline. None of these guest speakers heard any of their counterparts speak, yet all of them opened their addresses with apologetic, self-deprecating remarks clearly fueled by a sense of intimidation about a lack of musicianship or knowledge of music. Although they cloaked their remarks in humor, it was clear these professionals, who had attained a high degree of accomplishment in their own fields, felt a sense of isolation from basic musical processes and ineptness about their own music-making abilities. This particular group of people is not unique.

Consider the perspective of young children who have not yet entered the school music program. One evening, I was going back to the university to meet with undergraduate music education majors gathering to plan activities for the academic year. My wife had scheduled a prior 
commitment so I brought my threeyear-old daughter, Sophie, along with me. We met the students in the music education teaching lab, a room containing an array of classroom instruments. Remembering materials I needed from my office, I asked my daughter to stay in the teaching lab with the college students and assured her that I would be right back. On my return, I was surprised to find Sophie had organized the students into a small ensemble sitting crosslegged on the floor. She had assigned instruments to them and to herself and was proceeding to lead the group through a spontaneous improvisatory experience. In that short period of time, Sophie had exercised her role as a conductor, a performer, and a composer. Sophie is not special in this regard. She is, as are most children, simply willing to explore music making and creativity as a natural aspect of being human. Our profession has settled for an approach to music education that has left individuals disenfranchised of opportunities to confidently and knowledgeably embrace their own musicality. At the secondary level, this condition is perpetuated by a singular emphasis on large ensemble performance preparation as the primary mode of musical instruction. Bear in mind that performance is a vital component of an effective music education program. Few of us would have pursued music as a career if it were not for the profoundly stirring moments we have all experienced many times as performing musicians. After all, music is a performance art.

Yet, I want to clarify distinctions between healthy and unhealthy approaches of incorporating the performance component into music education programs at the pre-K-12 levels. In addition to performance, a well-rounded music program provides regular opportunities for students to develop expertise with creating music (composing, improvising, arranging), responding to music (listening, analyzing, critiquing, describing, and evaluating), and understanding music (synthesizing knowledge of music in relation to history, culture, heritage, and other content areas). Programs employing balance among all components treat performance as a means to the greater end of cultivating student expertise and consequently independent access to artistic endeavors (and the quality of life that accompanies such endeavors). Performances, especially those of the large ensemble, are included so students can experience practices and traditions associated with the art of music. Furthermore, performance offers a public display of what students have learned and can do as a result of that learning.

In less healthy programs, performance preparation is pursued as the lone activity in the class, without regard to other components (creating, responding to, and understanding music) and with minimal student engagement of critical thinking. The primary goal is to produce a polished performance of the highest quality possible; all student learning and skill development is subservient to this goal. In the end, public performance is a display of the director's expertise in assembling an ensemble and of his or her musicianship. In this paradigm, students' musical learning and skill development inessential to the performance outcome is acquired in a peripheral manner, if at all. Most music education programs at the secondary level are unfortunately more accurately characterized by the latter description than the former, with few programs fulfilling the totality of their professional obligations consistently. How did the profession settle on a tradition of teaching practice characterized by such an imbalance?

\section{Historical Perspective: How Did We Get Here?}


The idea of providing an education in music began in the United States as a pragmatic reaction to poor singing occurring in church congregations in the 1720s. When the singing school movement proliferated during the eighteenth and early-nineteenth centuries, so did the bonds tying musical activity to our nation's social fabric. Music education started in the United States with a natural emphasis on improving the quality of ensemble performance and has since deviated little from that purpose.

Around the beginning of the nineteenth century, the theories of Johann Heinrich Pestalozzi permeated educational thought in the United States. A forerunner of John Dewey, Pestalozzi believed the only true foundation of human instruction was acquired through direct experience with the senses (Keene 1987). Educators easily adapted these ideas to facilitate the development of singing skills. And so the die was struck to define music education in the United States as something involving active participation, the proof of which to be a performance result. Pestalozzi's music education followers missed his genuine intention of applying a child-centered approach to teaching and learning, one in which the development of each child's creative individuality is central. If music educators applied the totality of Pestalozzi's ideas, providing students the freedom to respond in a creative and original manner, perhaps the field of music education would be substantially different today.

Take Two?

The first half of the twentieth century presented another opportunity for the music education profession to reinvent itself as something that could blossom into a deeper, more meaningful music education for each individual child than the simple honing of notational reading and ensemble performance skills. The existing educational approaches at the start of the 1900s were rooted in social efficiency and emphasized classroom control, management, obedience to authority, and a structured curriculum focused on memorization and rote skills. A new approach to education, however, was beginning to take hold. The progressive education movement, most closely associated with John Dewey, was an outgrowth of Granville Stanley Hall's child study movement. Hall related child educational readiness to psychological and physiological stages of development and suggested the curriculum should come from the child and be based on his or her interests and needs. Dewey, a student of Hall, promoted the idea students should be encouraged to be critical thinkers, creative beings, and expressive about their feelings. What was learned needed to be experienced directly and subjected to scientific inquiry by the student to be understood fully.

The idea of direct experience fit well with the active nature of how music was being taught at the time. "Music, more readily than the academic disciplines [of the time], complied with the principle of experience made useful in actual performance" (Leonhard and House 1972, 62). However, music educators had limits to how far they could apply Dewey's ideas at the time.

[Music educators] were comfortable with [students] learning to read music and singing patriotic songs, but they were suspicious of sensitizing children to beautiful sound and color. Also suspect were teaching methods that spent time motivating children, or worse allowing them to decide what they would do on a given day. Dewey's pragmatism fit in with the "can do" attitude developed on the frontier, but many of the subtleties of the new 
relationship between teacher and learner did not. Often the teachers themselves, despite the benefits of workshops, graduate study, and lectures and demonstrations at MSNC and other professional meetings, did not change the atmosphere of their classrooms. (Mark and Gary 1992, 198)

The music-teaching profession was afforded a second chance to transcend its utilitarian beginnings, yet it masterfully took what supported the status quo and sidestepped what might have profoundly changed the course of music education.

Between 1910 and 1940 a dramatic expansion and subsequent geographic population shift worked to solidify large ensemble performance as a primary teaching mode of secondary music education. In that time, the percentage of high school-aged children who attended school increased from 10 percent to 75 percent, creating a need to calibrate curricula to accommodate this expansion in secondary school population. For music offerings, large ensembles served this purpose well. Furthermore, population shifts from rural to urban areas created a deficit of trained school music teachers. To remedy the situation, administrators hired professional performers to teach in the schools. "These musicians held 'rehearsals' much as one would in a professional group, and their whole orientation was directed toward performance" (Abeles, Hoffer, and Klotman 1996, 18).

The large ensemble performancebased mode of music education was further entrenched by the advent of music contests, a characteristic of public school music that exists today. From the onset, competitions provided a tangible method of generating excitement among the public for music education. In promoting the first national band contest in 1926, its organizers exclaimed, "a good school band can add more than perhaps anything else to the prestige of its school and town" (Mark and Gary 1992, 273).

With such high expectations, contest results soon became, and still are, an expedient way for administrators and the public to evaluate the effectiveness of a secondary school music program and, in an unspoken but real way, the effectiveness of the teacher. Given that assessment dictates instruction, the practice of music education at the secondary level had become increasingly about achieving higher and higher levels of the large ensemble performance quality. Not surprisingly, justifications for the inclusion of music at the secondary level often included elements that promoted a successful large ensemble performance result (i.e., the ability to contribute positively to a group, the development of sound work habits) rather than elements that facilitated students to mature along their individual roads toward musical independence.

Is the Third Time the Charm?

In a 1953 article appearing in the now-defunct journal Education, Charles Leonhard challenged the profession to abandon its propensity to argue the value of music education on extramusical claims. Instead, he professed "the real justification for the inclusion of music in the school curriculum lie [sic] in its unique and universal appeal and its unique value as a means of expressing symbolically the life of feeling" (Leonhard 1953, 23). Leonhard deftly defined the aesthetic musical experience as "simply one in which a person responds to the aural beauty of music" and thus, the aesthetic education movement in music began (24). Over the next thirty 
years, Charles Leonhard created a straightforward approach to every aspect of the profession in the effort to promote the singular idea that the purpose of music education was to develop musical understanding and musical responsiveness in all students. According to Leonhard, the job of the school music program was to "create a favorable musical environment, one in which every pupil can undergo the maximum musical growth consistent with his ability and his interests" (Leonhard and House 1972, 4, emphais added).

What made Leonhard's work so powerful was its synchronicity. Leonhard began his attempts at awakening the profession just several years prior to the launching of Sputnik and continued throughout a period of time in which particular attention was placed on education and what it should be doing for society. The launching of Sputnik was a historical event that sparked strong reactions among policymakers regarding our education system, the effects of which we are still feeling today. Efforts to ensure excellence in all aspects of education in the 1960s led to dire (and somewhat questionable) prognostications in the 1980s, which in turn, fueled rhetoric for Goals 2000 legislation and its consequent No Child Left Behind (NCLB) policy.

In this tumultuous period, advocacy efforts based in part on philosophical foundations and related benefits that come from students' involvement in comprehensive music and arts programs-namely opportunities for students to explore their creativity-preserved music's place in public school education (Mark 2002). Also during this time new frontiers, reminiscent of G. S. Hall's child study movement, were explored in the education field. Piaget's developmental stages, Vygotsky's social construction of knowledge, and Bruner's ideas of how children develop symbolic representations of the world all included common approaches to teaching that placed students at the center of their learning processes. Yet, amidst Leonhard's work, the advocacy rhetoric of professional organizations, and a growing child-centered education movement, many music educators (especially those at the secondary level) have maintained an unconscious disregard for most everything but the traditional practice of rehearsing toward performance as the fundamental activity in the music classroom. Currently, the academic year for a typical high school music ensemble consists of preparing for concerts and the all important district- and statelevel contests, with more thoughtful consideration afforded the question "What technical challenges do I need to prepare my students to accomplish so that we can perform the literature?" rather than the question "How can I best use encounters with the literature to facilitate musical independence in each student?"

\section{So Where Do We Go from Here?}

A growing number of forward-thinking individuals are expanding the definition of music education. Instead of the measure of success being "listen to what my group can do," it is evolving toward a student-centered measure of "look at what my students know, can do, and value about music." The introduction of the National Standards in 1994 and the subsequent adoption of various versions of those standards at state levels (all a familiar echo of the push for comprehensive musicianship in the 1960s and 1970s) have caused a number of music educators to consider regular incorporation of "extra-performance" teaching strategies in the effort to provide students with a comprehensive musiclearning experience.

\section{A Case Study}


Here is an example of one of those forward-thinking practitioners. Jim Smith (a pseudonym) began his teaching career much like most: preparing for concerts and contests. In his second year, after earning a second-division rating at the district-level contest (barring his group from going on to the statelevel contest), he was in a position of having rehearsal time and no immediate contest for which to prepare. Through a series of coincidences he found himself developing an interdisciplinary project with the choir, art classes, and English classes based on the Francis McBeth piece Of Sailors and Whales. The experience had such a positive impact on students, parents, and the community that something clicked inside Jim. From that point forward, he realized simply preparing for concert and contest performances alone was not activity worthy of the moniker "music education." Music education became about making rich connections for students: connections to the music, professional musicians, composers, other cultures, other arts, and even their own families.

\section{Connections to Visual Art}

One year, Jim programmed Scenes from the Louvre by Norman Dello Joio for an impending concert. The need to provide students with an opportunity to explore interdisciplinary connections between music and visual art motivated his choice. He called on a colleague in the school's art department who assembled and presented several lessons on the elements of art and on how color affects people. Furthermore, this art colleague led the class in a watercolor production activity in the school's cafeteria. He gave a 2-foot by 3-foot sheet of butcher paper and watercolor pigments of the three primary colors to each student, providing the challenge of mixing colors to produce any additional colors. He asked each student to choose one of the first four movements from the Dello Joio piece and, using guiding information from the art lectures, represent graphically what that movement meant to him or her. Although they were allowed to create either realistic or abstract representations, he required each student to explain his or her choices. Once the paintings were completed, they were displayed on the walls of the band room.

The lectures, the watercolor production activity, and student explanations took several class periods; however, the rich and meaningful experience was deemed well worth the time. Students provided explanations of their artistic decisions with amazing depth. The watercolor production activity enriched following rehearsals as Jim seized many opportunities to reference aspects of students' artworks as analogous to various ideas developed in the music (line, phrase, tone color, form, etc.). An unexpected benefit occurred on the evening of the performance when, afterward, the audience was invited to tour the band room to see the gallery of student artwork. As people entered the band room there was an almost instantaneous reversion among the students to being second graders as they enthusiastically grabbed their parents by the hand to proudly show their work. For a brief moment the wall of tension, all too common between parents and teenagers, dissipated. Later that year, the French club traveled to France and the band students in the club insisted an afternoon at the Louvre be included on the agenda.

Connections to Other Cultures through Folk Music

One September afternoon, while attending a local folk festival, Jim was enjoying the performance of a mother and daughter singing duo. As they sang sets of traditional Norwegian 
folk songs, Jim began to hear melodies that he recognized from Clare Grundman's band composition, Norwegian Folk Rhapsody. Immediately, he conceptualized a plan to program the Grundman piece and to invite the duo to make a presentation to the band students. On the day of the visit, the duo presented general information about Norway and about Norwegian folks songs, presented connections to the culture and climate of the area, performed, and taught the band students several Norwegian folk songs. Jim had even found a bakery that delivered Norwegian krumkake (a thin, crisp, cone-shaped cookie usually made during the Christmas holidays). On the evening of the concert, he invited the mother and daughter duo back to sing for the audience and, in the true tradition of folk singing, they taught the audience a few simple folk songs. As they finished the concert with an audience group singalong, the infamous divide that occurs frequently between performers and audience completely vanished.

\section{Connections to Professional Musicians (The Phone Interview)}

Periodically, Jim will take time from his rehearsals to facilitate conversations between his students and musical personalities from all over the country. He does this with the aid of a thirtydollar speakerphone connected to the band room sound system. The phone interview is an activity in which Jim will contact a musical personality (performer, composer, etc.) and arrange for an interview to take place during one of his band rehearsals. Prior to the interview, students are provided background information about the person being interviewed and are assigned to compose two to three questions, evaluated for quality and depth of thought. On the day of the interview, several students are selected randomly to ask their questions. Following the interview, all students are asked to write a one-to two-page reflection about what they learned during the interview. Jim has facilitated interactions with a variety of musicians, including Eddie Daniels, Frederick Fennell, Ron Nelson, Frank Battisti, Seiji Ozawa, and Pulitzer prizewinning composer Michael Colgrass. One of the students' favorite interviews was with Alex Bernstein, the son of Leonard Bernstein. Some of the initial questions revolved around what it was like growing up in a household with so many famous visitors, the Beatles being frequent guests. However, a wonderful learning moment occurred when Alex politely diverted attention away from the more glamorous aspects and affirmed that what was most treasured was the relationship with his father. To Alex, the time and experiences they shared together were most important.

\section{Connections to Composers}

One of the more common connections that Jim facilitates for his students is between them and composers of pieces for wind band and chamber winds. Since 1999 he has commissioned more than fifteen new compositions from composers such as David Gillingham, Augusta Reed Thomas, Libby Larsen, Clark McAlister, Michael Weinstein, Adam Gorb, Daniel Kallman, Scott McAllister, Timothy Mahr, Rolf Rudin, Lowell Liebermann, and Elliott Schwartz. Unlike the typical experience of contracting a composer to write a piece and possibly attend the premier performance, Jim looks for composers who are willing to visit the campus, meet the students, and discuss the composition process before starting on their pieces. Jim's primary concern is that his students gain an enhanced understanding of the composition process and the opportunity to get to know composers as human beings. 
During a recent commissioning project, Jim gave his students a creative experience of the highest quality. Libby Larsen is one of America's most prolific and most performed living composers and lives within twenty miles of Jim's school. As part of a recent project, Jim commissioned Larsen to write a piece for the band. During the project, Jim invited Larsen to visit the students periodically to discuss the creative process involved in composing music and to provide her perspective on composition projects that several groups of students were developing. On the evening of the premier, the concert was organized so that Ms. Larsen's piece composed the second half whereas the students performed their compositions in the first half. As a result of this process, Jim's students were not only given the opportunity to learn from Ms. Larsen, but also to see themselves as responsible agents in a creative decision-making process. I am convinced they left the experience with a less mystified concept of musical creativity and an empowered sense of their own musicianship.

\section{A Disposition in Need of Replication}

The previous paragraphs describe just a few of the many best practices that Jim Smith brings to his ensemble classroom. These practices exemplify an all-toorare disposition for music teaching and learning. Jim sees his role not simply as one who is responsible for assembling an ensemble capable of producing credible performances, but as one who facilitates for his students opportunities to uncover and assimilate rich artistic experiences into their lives regularly. His purpose for public performance is not to display his proficiency as a musical director, but to share with the community the accomplishments of his students and allow them to glimpse the powerful learning opportunities taking place in his classroom on a regular basis. Incidentally, Jim's groups have been invited regularly (through juried processes) to perform at state and national music education conferences. Furthermore, the performance quality of his groups has been described consistently as that rarely achieved by most high school and many college ensembles. Rather than pursuing his approach to teaching at the expense of performance quality, Jim maintains his conviction that facilitating all components of a healthy music education actually enhances the performance quality of his groups.

Jim honors the knowledge base and repertoire of experiences that his students bring when they enter the program. He works to continually broaden that foundation by providing formative experiences placing his students in creative roles and by bringing them in contact with highcaliber art and artists. As a result, it is not unusual for his students to seek out opportunities to attend symphony concerts and solo performances by acclaimed musicians and opportunities to attend art exhibitions, dance performances, and theater productions that visit the area. His students do not consider musical and artistic experiences as rare events to be admired as anomalies in life. Rather, they see such events as vital aspects of being human to be enjoyed, contemplated, discussed, and to serve as catalysts for transfiguration to a richer life.

Jim Smith and others like him epitomize what Leonhard (1999) describes as music teachers who "think critically about music and the teaching of it" (43). If such approaches and dispositions serve the highest goals of the music education profession, and they do, then a logical question follows. How can we facilitate the development of this kind of disposition in all of our prospective teachers? 


\section{How Music Teacher Education Can Contribute to Change}

The most logical place for substantive change in professional practice to occur is with music teacher education. The period during preservice teacher education and the first several years of induction into the profession represent a window of opportunity in which an expanded definition of music education might be developed in the minds of future teachers. Yet, with a long and well-established history of formal music teacher education in the United States there has been a failure to facilitate an evolution in how music education is delivered in pre-K-12 schools and specifically an inability to break the cycle in new teachers of teaching how they were taught. Too often, undergraduates complete our music teacher education programs and proceed to re-create their own public school music experience for their students.

If we are to take full advantage of the leverage we have as music teacher educators, we must look at the music teacher-education process through a sociological lens because potent sociological forces are affecting thinking and actions across the music education profession. We must identify and understand the forces in play so we can apply appropriate strategies in our teacher education efforts that will have substantive effects. If we are to take on the combined challenges of changing professional practice and of preparing teachers to effectively step into and mature in this new practice, it is imperative that we consider the theoretical constructs and ideas associated with these sociological influences. The following section is a primer on social interaction theory based on Raiber's work (2005).1

\section{Social Interaction Theory}

Social interaction theory is a set of ideas originally put forth by George Herbert Mead (Morris 1934) that explains how powerful forces of social settings tend to shape perception, thought, and, consequently, behavior. As a variant of behaviorists' stimulus-response model, social interaction theorists believe an interpretation step occurs between stimulus and response. By interpreting the stimulus through any one of a number of filters (i.e., musical taste, past experiences, cultural background), a person can vary his or her response. Because filters are developed through personal experience, each person's filter is different. The primary difference between behaviorism and social interactionism lies in the assumption accorded the stimulus. Behaviorists assume all persons will understand stimuli the same way. Meaning is therefore built into the stimulus and is transmitted to recipients when they encounter it. Social interactionists view stimuli as symbols, not as real objects. As such, stimuli become abstract representations of what is real. To determine what is real, each person must interpret stimuli and construct reality from whatever the symbols represent to him or her. With new experiences, meanings of symbols change and so follows behavior.

Gestures. Symbols used to convey shared meanings between several people are labeled gestures. Gestures can be many things; the way a person dresses, one's vocabulary, or the tools used in a trade or vocation are only a few possible gestures that could communicate ideas to another person. You may ask if each person's social filters are different, how might we share the same understanding of a gesture? Although none of our filters have been constructed in exactly the same manner, we do share some similar experiences, often the result of being part of the same 
culture or subculture. People of a group tend to adopt the gestures of that group and share group understandings about meanings of those gestures.

Social reference groups. When a group of people is organized, no matter how loosely, around a body of knowledge they have formed a social reference group. Meaningful shared gestures define the reference group and provide a context for interaction between its members.

Insiders and outsiders. Members of a reference group not only share meaningful gestures, but also use these shared meanings as a foundation for assumptions typically adopted by all group members. Sometimes assumptions are presented in overt ways with creeds and oaths members must recite and adopt. Often, however, assumptions tend to be implicit, simply embedded in the culture of the group. To understand what these assumptions may be, a person must become an insider to the group. An insider is someone who understands and can meaningfully share gestures of the group with others. They possess the body or bodies of knowledge necessary for communication within the group and share understanding with other group members.

Open and closed groups. The number of shared gestures necessary for group entrance depends on the nature of the group. Members of a relatively open group share few gestures; entrance requires one to share only a handful of meaningful gestures. Groups characterized by complex bodies of knowledge are considered closed. It takes many shared gestures to be viewed as an insider in such reference groups. Consider gestures needed for socialization in the reference group of mall shoppers as compared with the reference group of neurosurgeons. It is important to realize that socialization to these groups differs not because of the disposition of members, but because of differences in bodies of knowledge.

Professional significant other (PSO). How does an outsider attain insider status? At this point, there is an impasse between those with insider and outsider status. It is necessary to understand the body of knowledge to become an insider one, but cannot share these gestures meaningfully until he or she is an insider. How is this situation resolved? Often, it is accomplished through a PSO. A PSO is a group member who manifests the body of knowledge around which the group is formed. Furthermore, this person is one whose opinion matters most to the members of the group. Outsiders are willing to alter their social filters to match the interpretation of the significant other. With this change comes opportunities to share and understand meanings of group gestures. Thus, outsiders begin their journey to becoming insiders in the reference group. Once enough gestures are shared with other group members outsiders can lay claim to the body of knowledge and become insiders. This process is called socialization.

\section{Typical Socialization of Undergraduate Music Education Students}

Students enter as performers. When students enter music teacher education programs, the vast majority of them have not experienced the role of teacher. Rather, they have been members of their band, choir, or orchestra and have been socialized as performers. Prior to entering the university, they accumulated understandings of gestures shared by the performer social reference group. They have learned a specialized vocabulary relative to their instrument and to their roles as individual performers and contributing members of the large ensemble. They have logged countless hours in individual practice and in ensemble rehearsal. Furthermore, peers, teachers, 
parents, and most other social contacts have valued them for their accomplishment as performers. All of these gestures and many not listed here solidify the performer social reference group among our incoming students. Their PSO (typically their high school ensemble directors) are valued for being keepers and dispensers of musical knowledge.

What our incoming students think they know about music education typically consists of (a) believing they have learned much about being performers, (b) having PSOs that were good, positive people and in many cases, good musicians, and (c) enjoying being involved in music and wanting to share that enjoyment with others. Our incoming students actually know little about the real world of being an effective music educator. Their knowledge of how to determine content appropriate to be learned, of designing teaching strategies that best fit the learning modes of students, and all the rest of what a professional in music education needs to know is typically nonexistent.

... And continue as performers. During the freshman and sophomore years, the music education program track is relatively indistinguishable from the performance track. Students take three to four semesters of music theory and music history, little of which is taught with the intention of showing how the material is relevant to those intending to be music educators. Students participate in one or more large ensembles throughout the entirety of their programs, an experience that tends to supplant the former PSO (the high school director) with the university ensemble director, who is rarely an appropriate model for the student searching to belong to the group pre-K-12 music educator. 2 Furthermore, students experience one of the most powerful socializing agents found in postsecondary institutions: the intimacy of one-on-one instruction.

By the time music education students enter a music education methods course, 3 they have experienced four to five semesters of gesture sets actively pulling them toward membership in groups better labeled professional musician, music historian, music theorist, or college-level wind conductor, groups that do not serve adequately as primary models for those seeking entry into the music educators social reference group. 4 With graduation looming, music education courses become a series of items to be checked off the advisor's degree sheet. Field experience during the junior and senior years may begin to awaken some to their responsibilities as music educators, but the late start is no match for years of prior indoctrination. When researching the occupational identity of music education majors, L'Roy (1983) substantiated this dynamic and later Roberts (1991a, 1991b, 1993) verified it. Both researchers found music education majors to show a strong allegiance with full-time performers whereas their identities as future music educators remained weak even after exposure to information about instructional processes via their methods courses. L'Roy found that only those who were in or had completed student teaching exhibited a somewhat greater sensitivity to issues concerning instructional skills and working with students.

... And perpetuate the performancebased approach to music education. Once in the field, the young inexperienced music teacher must contend with the combination of a pervasive performance-based music teaching culture and a relative paucity of alternatives to that culture. He or she has little incentive and fewer resources to do anything but to continue learning how to make a band (choir or orchestra) sound like a band (choir or orchestra) in the effort to progress 
through a system that rewards success on the stage over most all else. And so the cycle continues.

\section{An Alternative Socialization for Music Education Students}

L'Roy's (1983) finding of increased sensitivity to substantive music education issues among those involved in student teaching, however, provides a clue to how we might adjust our teacher education efforts. Placing undergraduates in the teacher role is a variable significant in affecting music education students' sense of a teacher self. However, many questions surface. How early in the program should role development efforts begin? What strategies need to be implemented in our teacher education programs to establish a self-sustaining music educator social reference group? Are there ways to accelerate such a dynamic? In the pages that follow, I describe a model for undergraduate music teacher education that draws on social interaction theory to facilitate the type of disposition that honors an expanded definition of music education and truly exemplifies Leonhard's (1999) ideal of those who "think critically about music and the teaching of it" (43).

Begin before the beginning. A performance audition is typically required before entrance is granted to most postsecondary music programs. For potential music education students, some programs also require an interview with music education faculty. In these programs, students are sent interview questions several weeks in advance and are asked to bring their responses to the audition or interview. The questions are used to (a) uncover a potential music education major's experiences with and propensities toward leadership in and out of music teaching situations, (b) identify breadth and depth of experiences with music making across the choral and instrumental divide, (c) identify a PSO, and (d) determine a degree of commitment to music education in general.

This process helps distinguish potential music education majors who have begun to identify with the music educator social reference group. In addition to the obvious benefit of gaining valuable insight about incoming students, there are several important secondary benefits. Over successive audition and interview seasons, an institution's growing reputation begins to motivate future potential interviewees to seek experiences (leadership positions, secondary instrument skills, etc.) that will best prepare them for the interview. Even at this early stage, the insider-outsider dynamic begins to shape behavior. That same reputation alerts music teachers (current PSOs) to provide enhanced experiences for their students who express the desire to major in music education. Finally, the process facilitates improved communication between university performance and music education faculty as they meet to compare results of each other's evaluations.

In the freshman year. In a sociologically based undergraduate music teacher education model, the most important experience occurring in one's program is the Introduction to Music Education course. Here, students are introduced to healthy, accurate, and forward-thinking gestures that help them create an appropriate music educator social reference group as a template through which all subsequent coursework and professional experiences are perceived. From the beginning, experiences are provided emphasizing the concept that the program is not a collection of courses composing an advisor's degree sheet. Rather, one's program becomes the list of authentic questions he or she develops about the skills, knowledge, and dispositions that must be 
learned to be an effective music educator. This simple but profound shift begins to move the burden of responsibility for learning away from professors and onto students (or more accurately, preservice teachers). Their job is to get answers to their questions and, in doing so, they develop new, more complex questions. Coursework, professors, cooperating teachers, field experiences, libraries, professional organizations, professional journals, and any other means of professional information become resources for answers to their questions. Ideally, this habit will continue throughout their careers.

It is crucial that this introduction take place at the beginning of the program (a two-semester sequence throughout the freshman year) because it must balance the powerful gesture sets that occur traditionally from the beginning of one's undergraduate music degree program and actively pull music education undergraduates toward membership in other reference groups (professional musician, music historian, music theorist, etc.). Because the sequence must be carefully designed to monitor and respond to the students' sociological development, it should not be relegated to a graduate teaching assistant. Rather, it should be delivered by one possessing a keen understanding of the complex sociological dynamics that can take root and one who has enough longevity in a position to become one of several PSOs for preservice teachers. Four components imperative to the success of this introductory experience include opportunities for (a) active learning, (b) field experience, (c) the formation of a professional peer community, and (d) individual self-reflection.

Active learning. For gestures to be learned and internalized, class members must partake in activities that purposely use those gestures. It is especially important to include activities that place class members in the role of teacher. Peer teaching of simple five-to sevenminute nonmusical 5 tasks provides experience appropriate to elicit meaningful discourse about general teaching constructs such as (a) Schwab's (1969) four common places (learners, teachers, subject matter, and milieu); (b) Becker, Englemann, and Thomas's (1971) sequential patterns of instruction; (c) delivery skills (eye contact, facial expression, physical gesture, vocal inflection and projection, pacing, etc.); (d) planning and evaluation; and (e) the development and consistent use of a technical language. Such constructs are introduced at this level and are continually developed throughout the remainder of the program.

Field experience. Observation-rather than field teaching-is most needed at this early stage, however, it is important to be selective about the object of such field experiences. Observations of role models similar to Jim Smith, those exemplifying the highest ideals of the music education profession, can provide the catalyst for expanding traditional concepts of success (contest ratings and other group rewards) to include measures that promote and reward the development of pupils' individual expertise and musicianship (pupils' portfolios of compositions, improvisational skills, solo and small ensemble participation, knowledge of music theory and history, etc.). Early exposure to such innovative reward paradigms provides undergraduates the opportunity (time and experiences) throughout their program to accommodate traditional preconceptions and incorporate new ideas into their repertoire of what it means to be a music educator. Furthermore, observations at this stage provide opportunities to begin threads of discussion and questions around three primary characteristics of the students: cultural diversity, socioeconomic diversity, and exceptionalities. Last, observations can be used to highlight similarities and differences 
between the areas of instrumental, choral, and general music education, with an emphasis placed on the similarities.

Formation of a professional peer community. As music education undergraduates coalesce around common gesture sets and use shared meanings as a foundation for assumptions across the group, one of the most powerful aspects of social interaction theory begins to take place: the insider dynamic. This will occur naturally as undergraduates begin to value each other for their expertise with a growing number of professional gesture sets; however, the dynamic can be accelerated. One way to accelerate the development of a music teacher reference group is to initiate cocurricular and service-learning opportunities that provide informal teaching responsibilities for undergraduates. Complementary to the in-class peer teaching that is intended to highlight specific teaching constructs, less formal teaching opportunities (e.g., rehearsing a choir of senior citizens at the local nursing home or periodically visiting a local daycare and leading preschool students in singing) give preservice teachers practice with presenting themselves in front of groups of people and the opportunity to formulate new questions about music teaching and learning. Over the course of one's program, these cocurricular experiences become increasingly important opportunities to try out ideas uncovered in formal coursework and incorporate them into one's teaching repertoire. An additional way to accelerate the insider dynamic is by incorporating online dialogues through Blackboard, WebCT, or other Web-based virtual learning environments. With the aid of such virtual dialogue mechanisms preservice teachers can grapple with issues and ideas posted for discussion outside of the class meeting time.

Self-reflection. It is rare for incoming freshmen to bring an established habit of self-reflection. However, in a program that attempts to redefine music education and promote among its undergraduates the assumption of ownership for professional development, such a habit is imperative. From the literature, we know preservice teachers' beliefs influence a broad range of outcomes, including how preservice teachers approach teacher education, what they learn from it, and how (or if) they change (Calderhead and Robeson 1991; Richardson 1996). Furthermore, we know that preservice teacher's beliefs are tenacious (Carter and Doyle 1995) and are among the strongest predictors of future behavior (Anderson et al. 1995; Pajares 1992; Weinstein 1989). Often, however, such beliefs are so ingrained that they constitute unconscious assumptions of which the undergraduates themselves are often unaware. The regular practice of self-reflection can be an effective mechanism for helping to make explicit preservice teachers' beliefs about music education. Once implicit beliefs become explicit, they are available to be examined, refined, and reshaped.

Outcomes of the freshman year. There are two fundamentally dichotomous outcomes of an Introduction to Music Education course sequence; both are considered to be successful.

Outcome One: A portion of the students make a substantially greater commitment toward becoming music educators, seeing themselves as professionals in search of answers to their questions and seeing their undergraduate experiences as resources to have those questions answered. Students who make such a transition tend to take advantage of the richest opportunities that exist in their programs. 
Outcome Two: Another portion will make a substantially greater commitment away from becoming music educators and self-select into other career paths. Rather than meandering halfheartedly through a program and reaching a critical point of investment that propels one to finish an unwanted degree, these students can chart new directions for their futures.

In the sophomore, junior, and senior years. An undergraduate who has initiated the habit of taking responsibility for his or her own professional development begins to think and behave differently than the typical student. Furthermore, classes composed of undergraduates with high levels of professional commitment tend to create a particularly mature environment, a kind of chemistry. As a result, all subsequent coursework can be designed to tap into and build on this habit of enhanced professional responsibility. Additional strategies exist, however, that can be applied to accelerate the music teacher socialization process.

The combined conducting and teachingmethods sequence. In a typical program, conducting coursework (usually two semesters) and teaching-methods coursework (usually two semesters) are conceived, designed, and delivered as separate disciplines. Conducting instruction is approached primarily as a means to improve one's physical and artistic prowess with the baton whereas teaching-methods instruction emphasizes the pedagogical techniques for effective delivery of musical instruction. Consider the possibility of combining conducting credit hours with teaching-methods credit hours and delivering a multiple-semester sequence that addresses both areas simultaneously over a longer period than is available to each area separately. In such a model, conducting and music education faculty members could deliver coursework in a teamtaught fashion. Conducting skill could be presented and developed as an authentic pedagogical tool, the effectiveness of which improves with musical maturity.

Furthermore, such a model could take full advantage of the PSO dynamic. In a typical music teacher education program the PSO switches from the high school ensemble director to the collegelevel ensemble conductor, a role that for reasons described earlier does not serve adequately as a primary model for those seeking entry into the music educator social reference group. In a combined conducting and teaching methods sequence, faculty roles often merge (conducting professors frequently provide pedagogical knowledge whereas music education professors offer conducting information). With such blurring, class members often adopt faculty members from both disciplines as PSOs, a role that could eventually be accorded a highly functioning pre-K-12 teacher exemplifying the highest values of the profession (the most ideal outcome). For undergraduates who have explored alternative models of music education in an Introduction to Music Education sequence, endorsement from respected PSOs of what would be now familiar ideas helps to elevate class members' thinking about such innovative music teaching approaches beyond content "needed to be learned for a class" to an "I need to know this to be a successful music educator" mind-set.

Teaching musicianship to beginners (TMB). TMB serves two purposes. First, it provides a knowledge base and skill set for facilitating the development of tonal and rhythmic awareness (musicianship) of beginning choral and instrumental students in pre-K-12 settings. TMB, ideally situated after an initial general-music methods course, is a logical place to reference generalmusic method course content and tie together purposes common in general, choral, and instrumental music education. Second, TMB builds on executive skill foundations originally 
developed in instrumental and vocal techniques courses and extends that foundation to provide strategies for teaching group lessons at the beginning level. Technique courses grant a first pass at developing executive skills on secondary instruments, during which students' attention is absorbed primarily with such skill development. Most typical programs stop there. TMB provides an opportunity to revisit executive skills in a context of teaching those skills to others in a group setting. It is only after class members achieve a particular confidence with secondary instrument executive skills that they develop the need to know regarding teaching of those skills. Furthermore, TMB provides teaching strategies that merge musicianship and executive skill development, eventually offering beginning musicians a healthy foundation on which they can assimilate all subsequent musical experiences.

Cross-generational peer mentoring. To take full advantage of sociological implications associated with the model described earlier, it is important to consider order and placement of courses in the curriculum. Ideally, the model would be a five-year program that begins with the first-year Introduction to Music Education experience, a two-semester sequence designed to facilitate a heightened sense of individual responsibility for professional development in those who self-select to continue in the program. This foundation is followed by a four-semester conducting and methods course sequence delivered across the second and fourth years with the general music methods experience in the fourth semester, the TMB experience across the third year, and student teaching in the ninth or tenth semester (see table 1). The Conducting I, Conducting II, Methods I, and Methods II courses maintain traditional labels, mostly for administrative accountability of faculty load. In actual practice all four courses include equal mixes of conducting and methods components. Furthermore, fall semester courses (Conducting I and Methods I) can be scheduled to meet in the same room at the same time with the option for breaking into smaller groups that meet in several different rooms when needed. The same structure applies to spring semester courses (Conducting II and Methods II), allowing for a crossgenerational dynamic and peer mentoring possibility. When second-year and fourth-year students interact regularly in the same course the opportunities for gesture sets to be learned and for the music educator social reference group to be developed can occur at an accelerated pace. Second-year students value fourth-year students as insiders and work especially hard to attain such insider status. Furthermore, when given the opportunity to mentor younger class members, fourth-year students will solidify their knowledge base. One learns content best when he or she is placed in a position of teaching it to others. Last, such an intergenerational dynamic can bring professional peer-group formation, a component initially introduced in the first year, to a higher and substantially more mature level of operation.

TABLE 1. Five-Year Sequential Model

\begin{tabular}{|c|c|c|}
\hline \multirow[t]{2}{*}{ Year } & \multicolumn{2}{|c|}{ Semester } \\
\hline & Fall & Spring \\
\hline 1 & Introduction to music education I & Introduction to music education II \\
\hline 2 & Conducting I & Conducting II general music methods \\
\hline 3 & Teaching musicianship to beginners I & Teaching musicianship to beginners II \\
\hline 4 & Methods I (middle school-level content) & Methods II (high school-level content) \\
\hline 5 & Student teaching or finish core & Student teaching \\
\hline
\end{tabular}


Each semester of coursework includes a ten-hour field-experience component providing an authentic environment for music education majors to (a) apply content learned in coursework, (b) assimilate new ideas with prior conceptions, and (c) observe models of innovative teaching practice. Undergraduates completing second-year coursework have observed and worked with a variety of pre-K-12 students. Undoubtedly, some will present interesting examples of skill development challenges. Such field experiences generate a genuine need to know about proper approaches to skill development formation. As a result, undergraduates at this point are most ready and open to receive the ideas to be developed in TMB. Furthermore, the third-year TMB sequence provides an incubation period facilitating an enhanced maturity, serving fourth-year students especially well.

By the time undergraduates reach the fifth year, they have had eight semesters of fieldwork and a sequence of curricular and cocurricular experiences. This background promotes a level of maturity that can facilitate a smooth and seamless transition into student teaching. Of those who choose to student teach in the spring semester, some may want to use their fall semester as an opportunity to revisit the conducting and methods courses as teaching assistants, adding another layer of intergenerational dynamics to the experience for all involved. For programs with a fouryear cap, I have proposed a model that can be used to encourage social role development over a shorter time period (see table 2).

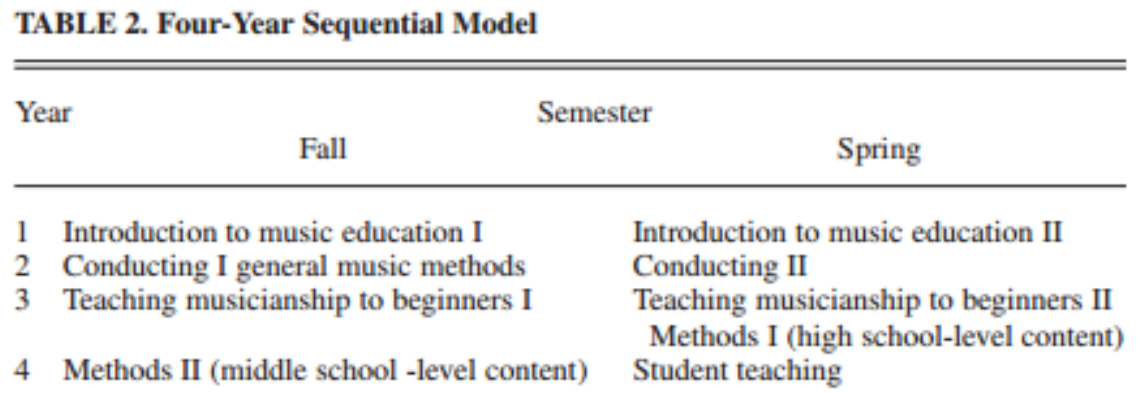

Postgraduation mentorship is an area that has received a good deal of attention from the profession in the past several years (Conway 2006; Conway and Christensen 2006; Conway et al. 2002; Haack and Smith 2000; Krueger 1999). This attention affirms music teaching as a highly complex venture and the idea that one can best process and negotiate such complexity as a teacher in the field rather than as a student in the university. Mentorship is suggested as an effective aid to facilitate one through those first several years. When new music teachers are also charged with the responsibility of implementing new practices, however, the complexity they face becomes compounded. The tradition of performance as an end (rather than as means to a greater end) continues to be a pervasive aspect of music education at the secondary level. If new ideas and practices are to be brought to the profession by its newest members, then a web of support for their ideas is essential. A combination of mentorship by forward thinking, experienced practitioners and regular interaction with peers who can support and empathize with each other's experiences may provide integrity needed to withstand the pressure of tradition. The 
profession has a long way to go to establish supportive policies if new teaching practices are to be embraced and implemented on a regular basis.

\section{Conclusion}

Many of the ideas in this article may look familiar. After all, we have included reflective journaling, field experience, and, in many cases, active learning in our music education methods courses for some time now with mixed results. The ideas in this article are different because they are founded on a theoretical model (social interaction theory) that can be used to guide curricular design and to monitor implementation of that design. Such monitoring is imperative because it is only when theoretical ideals are merged with practical application that a new approach can be sustained.

The model proposed is just one of a number of possible approaches to music teacher education that could be developed based on social interaction theory. Such models hold great promise for facilitating a reconceptualized approach to music teacher education and ultimately a reconceptualized approach to music education in general. These ideas are in profound need of a research base, especially one that explores the degree to which such theoretical constructs exist in music teacher education specifically. At the same time, however, the profession is in profound need of alternatives to the traditional music teacher-education approach that leads currently to an all-too-common manifestation of music education at the secondary level (teaching to the performance). As the effects of NCLB legislation persist in pushing music and the arts out the door, we cannot continue to rely on public performance of the large ensemble as our profession's primary evidence for one's musical learning. In a broader perspective, NCLB is only a symptom of society's growing request for greater accountability in all areas of education. It is unfortunate that we do not have the luxury of waiting while a careful and objective research base is assembled before taking action. We must act now on common sense ideas and conduct research along the way. There are currently four or five music teacher education programs across the country implementing social interaction theory, each with promising initial success and some (those having been in existence longer) with substantial longterm success in producing new music teachers who bring a visionary perspective of their role as music educators and an expanded definition of music education to the profession.

Perhaps the current period, made complex by a changing environment of education and society and by a growing recognition of new models for music teacher preparation, marks a fourth opportunity (alongside the efforts of Pestalozzi, Dewey, and Leonhard) for the music education profession to blossom into the fullest possible manifestation of education in the arts. I believe that a healthy, vibrant future for music education, one that enjoys incontrovertible relevance in the minds of policymakers, depends on the implementation of pedagogical approaches that facilitate for all students the cultivation of informed musical taste and expertise through the development of knowledge, feeling, and skill. This can only happen, however, if we rethink how we facilitate the development of future music educators.

\section{Notes}


1. This short primer on social interaction theory is adapted closely from Raiber (2005) and is included in this article with Raiber's permission. In his 2005 piece, Raiber also explains two additional theories that draw on sociological principles (Fuller's [1969] Levels of Concerns and Becker and Carper's [1956a, 1956b] Occupational Role Development) and describes an instrumental music teacher education program based on applications of all three theories. This information can provide a rich and useful background to persons adopting a sociological approach to music teacher education.

2. Of course, the university ensemble director may provide wonderful models of leadership, organization, ensemble rehearsal expertise, and personality traits. However, his or her primary responsibility is to tap group members' preexisting knowledge and skill sets to produce ensemble performances of the highest quality. Conversely, pre-K-12 music educators are responsible for facilitating musical growth and for establishing a baseline of musical knowledge, skill sets, and dispositions to promote students' lifelong involvement in music. Although musical expertise is associated with both of these professional roles (university ensemble conductor and pre-K-12 music educator) each carries distinctly different responsibilities to the students being served. As such, one role does not serve adequately as a primary model for the other.

3. The term music education methods course refers to those courses that deliver information about structuring music programs in the pre-K-12 schools and typically include pedagogical, administrative, and philosophical content. This is in contrast to the term techniques course, which refers to those courses that facilitate instrumental skill development, mostly on secondary instruments and voice.

4. Each of these professional roles carries distinctly different responsibilities to the students they serve. Although skills associated with each role are essential for a music educator to possess, none of these roles serves adequately as a primary model for the role of pre-K-12 music educator (Paul 1998).

5. Nonmusical tasks are employed to maintain attention on general teaching constructs intended to be highlighted and to reduce potential confusion about complex methodological approaches associated with particular musical concepts learned in future coursework.

\section{References}

Abeles, H. F., C. R. Hoffer, and R. H. Klotman. 1996. Foundations of music education. 2nd ed. New York: Schirmer.

Anderson, L. M., P. Blumenfeld, P. R. Pintrich, C. M. Clark, R. W. Marx, and P. Peterson. 1995. Educational psychology for teachers: Reforming our courses, rethinking our roles. Educational Psychologist 30 (3): 143-57.

Apfelstadt, H. 1989. Musical thinking in the choral rehearsal. In Dimensions of musical thinking, ed. E. Boardman, 73-89. Reston, VA: Music Educators National Conference.

Becker, H. S., and J. Carper. 1956a. The elements of identification with an occupation. American Sociological Review 21:341-48.

1956b. The development of identification with an occupation. American Journal of Sociology 61 (4): 289-98. 
Becker, W. C., S. Englemann, and D. R. Thomas. 1971. Teaching: A course in applied psychology. Chicago: Science Research Associates.

Bloom, B. S. 1956. Taxonomy of educational objectives: Handbook 1. Cognitive domain. New York: David McKay.

Calderhead, J., and M. Robeson. 1991. Images of teaching: Student teachers' early conceptions of classroom practice. Teaching and Teacher Education 7 (1): 1-8.

Carter, K., and W. Doyle. 1995. Preconceptions in learning to teach. The Educational Forum 59 (4): $186-95$.

Conway, C. M. 2006. Navigating through induction: How a mentor can help-mentoring beginning teachers can help both mentor and mentee by expanding the knowledge and expertise of each. Music Educators Journal 92 (5): 56-61.

Conway, C. M., and S. Christensen. 2006. Professional development and the beginning music teacher. Contributions to Music Education 33 (1): 9-25.

Conway, C. M., P. J. Krueger, M. Robinson, P. A. Haack, and M. V. Smith. 2002. Beginning music teacher induction and mentoring: A cross-state perspective. Arts Education Policy Review 104 (2): 9-17.

Covey, S. R. 1989. The seven habits of highly successful people. New York: Simon and Schuster.

Fuller, F. 1969. Concerns of teachers: A developmental conceptualization. American Educational Research Journal 6:207-26.

Haack P. A., and M. V. Smith. 2000. Mentoring new music teachers. Music Educators Journal 87 (3): 23-27.

Keene, J. A. 1987. A history of music education in the United States. Hanover, NH: University Press of New England.

Krueger, P. J. 1999. New music teachers speaking out on mentoring. Journal of Music Teacher Education 8 (2): 7-13.

Leonhard, C. 1953. Music education-aesthetic education. Education 73 (1): 23-26. 1964. The place of music in our elementary and secondary schools. Music Educators Journal 50 (4): 53-4, 57. 1985. A realistic rationale for teaching music. Reston, VA: Music Educators National Conference. ERIC rep. no. ED272426. 1999. A challenge for change in music education. Music Educators Journal 86 (3): 40-43.

Leonhard, C., and R. W. House. 1972. Foundations and principles of music education. 2nd ed. New York: McGraw-Hill.

L'Roy, D. 1983. The development of occupational identity in undergraduate music education majors. PhD diss., North Texas State University.

Mark, M. L. 2002. A history of music education advocacy. Music Educators Journal 89 (1): 44 48.

Mark, M. L., and C. L. Gary. 1992. A history of American music education. New York: Schirmer.

Marzano, R. J., R. S. Brandt, C. S. Hughes, B. F. Jones, B. Z. Pressiesen, S. C. Rankin, and C. Suhor. 1988. Dimensions of thinking: A framework for curriculum and instruction. Alexandria, VA: Association for Supervision and Curriculum Development.

Morris, C. W., ed. 1934. Mind, self, and society. Chicago: University of Chicago Press.

Pajares, M. F. 1992. Teachers' beliefs and educational research: Cleaning up a messy construct. Review of Educational Research 62 (3): 307-32. 
Paul, S. J. 1998. The effects of peer teaching experiences on the professional role development of undergraduate instrumental music education majors. Bulletin of the Council for Research in Music Education 137:73-92.

Raiber, M. A. 2005. Music teacher education: The emerging professional. Paper presented at the 2005 Symposium on Music Teacher Education, Greensboro, NC.

Richardson, V. 1996. The role of attitudes and beliefs in learning to teach. In Handbook of research on teacher education, 2nd ed., ed. J. Sikula, T. J. Buttery, and E. Guyton, 10219. New York: Macmillan.

Roberts, B. A. 1991a. A place to play. The social world of university schools of music. St. John's: Memorial University of Newfoundland Faculty of Education. . 1991b. Musician. A process of labeling. St. John's: Memorial University of Newfoundland Faculty of Education. . 1993. I, musician. Toward a model of identity construction and maintenance by music education students as musicians. St. John's: Memorial University of Newfoundland Faculty of Education.

Schwab, J. J. 1969. The practical: A language for curriculum. School Review 78 (1): 1-23. Weinstein, C. S. 1989. Teacher education students' preconceptions of teaching. Journal of Teacher Education 40 (2): 53-60. 